\title{
Short comunication: how to prevent chemotherapy medication errors?
}

Keywords: chemotherapy medication, morbidity, mortality, vinblastin, vincristine

\section{Introduction}

Chemotherapy medication errors are source of some morbidity and significant mortality. The overall error rates for the two hospitals were 1.35 and 1.77 per 100-patientdays, and 4.9 and 4.5 per 1,000 medication orders, respectively. ${ }^{1}$ Prevention from these complications should be addressed to the new staff and nurses in the oncology wards. It should be differentiated from adverse drug reactions which is another important source of injuries both in hospitalized and outpatients.

\section{Method}

The databases CINAHL, PubMed, Science Direct and Synergy were searched from 1988 to 2017 using the keywords medication errors, medication management, medication reconciliation, medication knowledge and mathematical skills, and reporting medication errors. Contributory factors to nursing medication errors are manifold, and include both individual and systems issues. These include medication reconciliation, the types of drug distribution system, the quality of prescriptions, and deviation from procedures including distractions during administration, excessive workloads, and nurse's knowledge of medications. It must be believed that the reported cases are tip of an iceberg of errors that are not published.

\section{Results}

Important examples of errors were: Miscommunicated verbal orders; Total course or cycle dose given every day inspite of weekly or every two weeks or over three consecutive days; Lack of pertinent patient health care information (i.e.: lab data and patient demographics such as age, height, weight and surface area); Use of incorrect patient information/lab data or the information/lab data for another patient; Excessive interruptions during order processing or dose prepration (Phone, patients' ring, pagers, etc); Poor packing and labeling by manufacturers; Poor communication between pharmacy and the nursing and medical staff; Use of abberevations of drug names (example: Vin for Vinblastin, Vincristine and Vinorelbine); Similar sounding drug names within the therapeutic class (example: Doxorobicin, Daunorubicin); Use of trade names which may vary even for generically available agents; Lack of warning stickers or labels to prevent inadverent intrathecal administration of drugs such as Vincristine, Vinblastine, Doxorobicin and Daunorubicin; ${ }^{2}$ Failure to round drug doses which potentialyy leading to a 10 fold overdose if the decimal point is not seen; Widely differing dosing regimens for the same tumor type (example: various regimens of 5-Fluorouracil in colorectal cancer) or in various tumors; Use of outdated lab data(example: serum creatinin or liver function tests for dose modification of certain medications).

Also there are some error prone medical transcriptions, for example: qd or QD for daily doses; qn, qhs, hs, bt for bedtime; $\mathrm{x} 3 \mathrm{~d}$ for $\mathrm{x}$ 3days; per OS for orally or PO (misread as for left eye!); Failure to use a zero before a decimal point when the dose is less than a whole
Volume 5 Issue $6-2017$

\author{
Mahdi Shahriari,' Babak Abdolkarimi \\ 'Shiraz University of Medical Sciences, Iran \\ ${ }^{2}$ Lorastan University of Medical Sciences, Iran
}

Correspondence: Babak Abdolkarimi, Lorastan University of Medical Sciences, Khorramabad, Iran,

Email b.abdolkarimi@yahoo.com

Received: August 12, 2017 | Published: November 28, 2017

unit (example: avoid $0.1 \mathrm{mg}$ instead of $0.1 \mathrm{mg}){ }^{3}$

Practical Guide for physicians: Please do: (1) Always doublecheck the dose against the actual drug regimen or protocol. (2) Always Use the full name (generic names preferred over the trade name) of the drugs. (3) Prescribe all drug doses clearly in terms of dose (example: $\mathrm{mcg}$, mg, grams, etc). (4) Use a leading zero when the dose is less than 1 (write $0.1 \mathrm{mg}$ not $0.1 \mathrm{mg}$ which may be read as $1 \mathrm{mg}$ ). (5) Always round chemotherapy doses greater than $5 \mathrm{mg}$ to the nearest reasonable amount and avoid excessive attempts at precision (i.e., for Cisplatin write $125 \mathrm{mg}$, not $126.4 \mathrm{mg}$, and for Carboplatin, write $900 \mathrm{mg}$, not $898.57 \mathrm{mg}$ ). (6) Date all orders with day, month and year, also include the time of the day for inpatients. (7) Use body surface area dosing $\left(\mathrm{mg} / \mathrm{m}^{2}\right)$ or for infants less than one year $\mathrm{mg} / \mathrm{kg}$ or $\left.\mathrm{mcg} / \mathrm{kg}\right)$. (8) Write the daily dose not the course dose (example: in a patient with body surface area of $1.5 \mathrm{~m}^{2}$, Cisplatin $20 \mathrm{mg} / \mathrm{m}^{2}$ per day for 5 days should be written: Cisplatin $30 \mathrm{mg} /$ day for 5 da Dys, neither $100 \mathrm{mg} / \mathrm{m}^{2}$ per course nor $150 \mathrm{mg} /$ course). ${ }^{4}$ (9) Avoid verbal order for the initiation of chemotherapy, but you may immediately stop chemotherapy by verbal order in the case of adverse reaction. (10) Realize that errors can and will happen at your wards, so create a committee of patient safety, develop a medication process improvement, prepare guidelines of drug preparation and teach new nurses and staffs. (11) If available, please use computerized physician order entry (POE) systems, which has been shown to reduce most of non-missed medication errors including dose errors, frequency errors, route errors, substitution errors and allergies.(last references). ${ }^{5,6}$

Please Don't: (1) Don't Use trade names, brand names, nicknames instead of generic names because for example "Aredia" which is a trade name for Pamidronate may be misconducted as "Adriamycin" or vice versa. (2) Don't write drugs in terms of ampoules or vials. Drugs have more than one vial or ampoule size (Vincristine has both 1 and $2 \mathrm{mg}$ vials, Furesemide has 10, 20 and 40mg ampoules, Cisplatine has 10 and $50 \mathrm{mg}$ vials, etc).

Practical guide for nurses: (1) Nurses should ensure the five principles of medication administration: The correct medication should be prescribed for the correct patient, in the correct dosage, via the correct route, and timed correctly (known as five rights). (2) Double check all new orders with another nurse on the same shift or incoming shift to ensure each patient's order and the medication administration record. 


\section{Conclusion}

Chemotherapy medication errors are not infrequent and should be considered that they may happen in your ward, by you and your personals, so a patient safety committee and annual education of all the staff is advisable, although new nurses should be trained on arrival. The guideline and continuous education program should be considered. Observation of trainees by authorized staff is suggested.

\section{Acknowledgements}

None.

\section{Conflict of interest}

The author declares no conflict of interest.

\section{References}

1. Folli HL, Poole RL, Benitz WE, et al. Medication Error Prevention by Clinical Pharmacists in Two Children's Hospitals. Pediatrics. 1987;79(5):718-722.
2. Fortescue EB, Kaushal R, Landrigan CP, et al. Prioritizing strategies for preventing medication errors and adverse drug events in pediatric inpatients. Pediatrics. 2003;111(4 Pt 1):722-729.

3. Leonard MS. Patient safety and quality improvement: medical errors and adverse events. Pediatr Rev. 2010;31(4):151-158.

4. Schwappach DLB, Marc-Anton Hochreutener MA, Wernli M. Oncology Nurses' Perceptions About Involving Patients in the Prevention of Chemotherapy Administration Errors. Chemotherapy ONF. 2010;37(2):E84-E91.

5. Bates DW, Teich JM, Lee J, et al. The impact of computerized physician order entry on medication error prevention. J Am Inform Assoc. 1999;6(4):313-321.

6. Bates DW, Leape LL, Cullen DJ, et al. Effect of computerized physician order entry and a team intervention on prevention of serious medication errors. JAMA. 1998;285(15):1311-1316. 